professed revulsion toward Medusa, whatever she might mean to him, for I was unable to locate Medusa in any of Sada Sami's dreams. And is it not the anthropologist himself who turns his analytic mirror upon her?

In my review, I praised Obeyesekere for admitting to the presence, and significance, of deep emotional responses on his part toward his informants. Too many social (and natural) scientists attempt to conceal the effect of their own humanity on their work. Those who own up to their feelings are more vulnerable to charges of nonobjectivity than are their more close-mouthed colleagues, but the works of the former are, in my opinion, more truthful and more scientific.

Finally, I apologize for any "distortions" that may have been present in my review. Considerations of space did not allow me to do full justice to this very complex work.

Margaret T. Egnor Hobart and William Smith Colleges

\title{
On Review of Discipline
}

Although I am aware that legitimate criticisms might be made regarding the thesis of my book, Discipline: The Canonical Buddhism of the Vinayapitaka, Robert Buswell, Jr. is wide of the mark in his recent review in JAS (42, no. 2 [1983]: 436-37). If I understand him correctly, his chief complaint is that I have "transposed" the significance of discipline for "the gradual path of spiritual development as ourlined in the Nikayyas" by viewing it solely as an "end product" rather than as "the initial catalyst of the path of training" (p. 436). First, my thesis was not centrally concerned with complementary formulations of the path that can be found within the four Nikayas, but with the specific manner in which discipline is understood within the context of Vinaya literature. Second, there are numerous occasions within the Mahävagga account of the Buddha's missionary activities in which converts attain the Dhamma-Eye suddenly after hearing the Buddha preach the Four Noble Truths. Clearly, the text does not portray a "gradual path" in these instances. And finally, Buswell has obscured my interpretation by saying that discipline is viewed in my book only as an "end product." My point is that, as I indicate on page 84 , discipline requires mindfulness. Vinaya is a mental discipline. But more importantly, and thus laying bare the inaccurate appraisal offered by Buswell, I state clearly toward the end of my discussion on Upasampadā (pp. 115-16) that "discipline is the means by which the individual may demonstrate his worthiness to become a full-fledged member of the monastic order." I have not argued the exclusivity of discipline as an "end product" or as an "initial catalyst." Rather, I have simply demonstrated that the Vinaya sees discipline as an affective expression of Dhamma. 